\title{
Tumor Necrosis Factor Receptor 1 and Its Signaling Intermediates Are Recruited to Lipid Rafts in the Traumatized Brain
}

\author{
George Lotocki, ${ }^{2,3}$ Ofelia F. Alonso, ${ }^{2,3}$ W. Dalton Dietrich, ${ }^{2,3}$ and Robert W. Keane ${ }^{1}$ \\ Departments of ${ }^{1}$ Physiology and Biophysics and ${ }^{2}$ Neurological Surgery, and ${ }^{3}$ Miami Project to Cure Paralysis, University of Miami School of Medicine, \\ Miami, Florida 33136
}

\begin{abstract}
The tumor necrosis factor (TNF) ligand-receptor system plays an essential role in apoptosis that contributes to secondary damage after traumatic brain injury (TBI). TNF also stimulates inflammation by activation of gene transcription through the I $\kappa \mathrm{B}$ kinase (IKK)/NF- $\kappa \mathrm{B}$ and JNK (c-Jun N-terminal protein kinase)/AP-1 signaling cascades. The mechanism by which TNF signals between cell death and survival and the role of receptor localization in the activation of downstream signaling events are not fully understood. Here, TNF receptor 1 (TNFR1) signaling complexes in lipid rafts were investigated in the cerebral cortex of adult male Sprague Dawley rats subjected to moderate (1.8-2.2 atmospheres) fluid-percussion TBI and naive controls. In the normal rat cortex, a portion of TNFR1 was present in lipid raft microdomains, where it associated with the adaptor proteins TRADD (TNF receptor-associated death domain), TNF receptorassociated factor-2 (TRAF-2), the Ser/Thr kinase RIP (receptor-interacting protein), TRAF1, and cIAP-1 (cellular inhibitor of apoptosis protein-1), forming a survival signaling complex. Moderate TBI resulted in rapid recruitment of TNFR1, but not TNFR2 or Fas, to lipid rafts and induced alterations in the composition of signaling intermediates. TNFR1 and TRAF1 were polyubiquitinated in lipid rafts after TBI. Subsequently, the signaling complex contained activated caspase-8, thus initiating apoptosis. In addition, TBI caused a transient activation of NF- $\kappa \mathrm{B}$, but receptor signaling interacting proteins IKK $\alpha$ and IKK $\beta$ were not detected in raft-containing fractions. Thus, redistribution of TNFR1 in lipid rafts and nonraft regions of the plasma membrane may regulate the diversity of signaling responses initiated by these receptors in the normal brain and after TBI.
\end{abstract}

Key words: tumor necrosis factor; apoptosis; traumatic brain injury; lipid rafts; intracellular signaling; inflammation

\section{Introduction}

Tumor necrosis factor (TNF)- $\alpha$ is a prominent proinflammatory cytokine that has been associated with various neurodegenerative diseases (Tyor et al., 1995; Clark and Lutsep, 2001; Lou et al., 2001; Perry et al., 2001; Probert and Akassoglou, 2001; Shinoda et al., 2003). Its function in the pathogenesis of neural injury remains unclear, however, because both neurotoxic and neuroprotective effects after injury have been described (Bruce et al., 1996; Nawashiro et al., 1997; Kim et al., 2001; Martin-Villalba et al., 2001; Yang et al., 2002). Traumatic brain injury (TBI) induces upregulation of TNF- $\alpha$ protein and mRNA in the injured cortex (Taupin et al., 1993; Fan et al., 1996; Shohami et al., 1996, 1997; Vitarbo et al., 2004), and increased levels of TNF- $\alpha$ have been reported in plasma and CSF of head-injured patients (Ross et al., 1994). Gene-targeting studies indicate that the presence of TNF- $\alpha$ in the acute posttraumatic period may be deleterious, whereas this cytokine may play a beneficial role in the chronic

Received July 22, 2004; revised 0ct. 29, 2004; accepted 0ct. 31, 2004. This study was supported by National Institutes of Health Grants NS30291 and NS42133.

Correspondence should be addressed to: Robert W. Keane, Department of Physiology and Biophysics, 1600 Northwest 10th Avenue, Miami, FL 33136. E-mail: rkeane@miami.edu.

DOI:10.1523/JNEUROSCI.3823-04.2004

Copyright $\odot 2004$ Society for Neuroscience $\quad$ 0270-6474/04/2411010-07\$15.00/0 period after TBI (Schwenzer et al., 1999). Thus, TNF signaling after TBI involves both cell survival and apoptosis.

Mammalian TNF- $\alpha$ signals through two cell surface receptors: TNFR1 (CD120a) and TNFR2 (CD120b). Most cells constitutively express TNFR1, whereas TNFR2 expression is highly regulated. Activation of TNFR1 leads to the recruitment of the adaptor TNFR-associated death domain protein (TRADD), which serves as a platform to recruit additional signaling adaptors (Hsu et al., 1995, 1996). TRADD binds the Ser/Thr kinase receptor-interacting protein (RIP) and TNFR-associated factors 2 (TRAF2) and 5 (TRAF5). This TRADD-RIP-TRAF complex causes activation of NF- $\kappa$ B through an unknown mechanism (Liu et al., 1996; Ting et al., 1996; Kelliher et al., 1998; Devin et al., 2000). TRAF2 can also recruit secondary adaptors that modulate signaling, i.e., TRAF1 and cellular inhibitor of apoptosis protein-1 (cIAP-1) and cIAP-2 (Shu et al., 1996). cIAP-1 supports ubiquitination and proteasomal degradation of TRAF2 (Li et al., 2002), whereas TRAF2 inhibits signaling through TNFR2 by an unknown process (Wajant et al., 2003). Additionally, TNFR1 can recruit caspase- 8 via TRADD and Fas-associated death domain protein (FADD) to induce apoptosis (Hsu et al., 1996).

Redistribution of TNFR1 in the plasma membrane is one possible mechanism for regulating the efficiency of TNF signaling. 
Recent in vitro evidence suggests that redistribution of TNFR1 into specialized microdomains (lipid rafts) may account for the outcome of some TNF- $\alpha$-activated signaling pathways (Cottin et al., 2002; Legler et al., 2003), but TNFR1 localized to nonraft regions of the plasma membrane are capable of initiating different signaling responses (Doan et al., 2004); however, the role of microdomains in signal transduction emanating from the TNFR family in vivo has not been addressed. Here we show that TNFR1 is present in lipid rafts in normal rat cerebral cortex. TBI induced a rapid recruitment of TNFR1 into lipid rafts and altered associations with signaling intermediates. Thus, redistribution of TNFR1 into lipid rafts may contribute to pathomechanisms that account for the specificity of CNS cell death after TBI.

\section{Materials and Methods}

Fluid-percussion brain injury. The University of Miami Animal Care and Use Committee approved all procedures. Male Sprague Dawley rats $(n=$ 5 per group) weighing 250-350 gm were anesthetized using 3\% halothane and a gas mixture of $70 \% \mathrm{~N}_{2} \mathrm{O}$ and a balance of $\mathrm{O}_{2}$ to achieve deep sedation. The animals were then intubated endotracheally and mechanically ventilated using a Harvard rodent ventilator (Harvard Apparatus, Holliston, MA) at a mixture of $70 \% \mathrm{~N}_{2} \mathrm{O}, 0.5-1.5 \%$ halothane, with a balance of $\mathrm{O}_{2}$ adjusted, as described above. Pancuronium bromide $(0.5$ $\mathrm{mg} / \mathrm{kg}$, i.v.) was administered every hour during the surgical procedure to facilitate mechanical ventilation. The femoral artery and vein were cannulated with a PE-50 cannula for purposes of drug administration and blood sampling for serum glucose, arterial blood gas determination, and continuous arterial blood pressure monitoring. Rectal and temporalis muscle thermometers were placed and self-adjusting feedback external warming lamps were used to maintain a core temperature of $37^{\circ} \mathrm{C}$. Arterial blood gases were measured $15 \mathrm{~min}$ before and after TBI.

To produce TBI, animals were then placed in a stereotaxic frame for introduction of a rat parietal craniotomy, as described previously (Keane et al., 2001). A fluid-percussion injury device was connected to the tubing $24 \mathrm{hr}$ after craniotomy, and rats were subjected to moderate $(1.8-2.2$ atmospheres) levels of TBI (Keane et al., 2001). After TBI, all rats were returned to their cages and allowed to recover from the surgical procedures. At the time they were killed, animals were deeply reanesthetized with halothane. Naive rats $(n=5)$ were anesthetized and killed. Tissue samples were snap-frozen in liquid nitrogen and stored at $-80^{\circ} \mathrm{C}$ until the time of assay.

Antibodies. Mouse anti-TNFR1 monoclonal (1:500), mouse antiTNFR2 monoclonal (1:500), mouse anti-TRAF1 monoclonal (1:500), mouse anti-TRAF2 monoclonal (1:500), mouse anti-caspase- 8 monoclonal (1:500), mouse anti- $\beta$-tubulin monoclonal (1:1000), rabbit antiTNFR1 polyclonal (1:500), and rabbit anti-TNFR2 polyclonal (1:500) antibodies were obtained from Santa Cruz Biotechnology (Santa Cruz, CA). Mouse anti-caveolin-1 monoclonal (1:1000), mouse anti-Fas monoclonal (1:5000), mouse anti-RIP monoclonal (1:1000), mouse anti-TRADD monoclonal (1:250), mouse anti-I $\kappa$ B kinase (IKK) $\beta(0.25$ $\mu \mathrm{g} / \mathrm{ml})$, and mouse anti-flotillin-1 monoclonal (1:250) antibodies were obtained from BD Biosciences (San Diego, CA). Rabbit anti-cIAP-1 polyclonal $(1 \mu \mathrm{g} / \mathrm{ml})$ and anti-cIAP-2 polyclonal $(1.5 \mu \mathrm{g} / \mathrm{ml})$ antibodies were obtained from Trevigen (Gaithersburg, MD). Rabbit anti-FADD polyclonal (1:500), mouse anti-ubiquitin monoclonal (1:500), and rabbit anti-ubiquitin polyclonal (1:500) antibodies were purchased from Chemicon International (Temecula, CA). Rabbit anti-IKK $\alpha$, anti-I $\kappa \mathrm{B}-\alpha$, and anti-phospho-I $\kappa \mathrm{B}-\alpha$ (1:1000) were purchased from Cell Signaling (Beverly, MA).

Isolation of lipid rafts from rat cortex. Detergent-resistant membranes from adult rat cortices were isolated on the basis of their insolubility in Triton $\mathrm{X}-100$ at $4^{\circ} \mathrm{C}$ and their ability to float in density gradients. Rat cortices were homogenized in a dounce homogenizer in $1.5 \mathrm{ml}$ of PTN 50 buffer (50 mm sodium phosphate, pH 7.4, 1\% Triton X-100, $50 \mathrm{~mm}$ $\mathrm{NaCl}$ ) containing $10 \mathrm{~mm}$ DTT, $1 \mathrm{~mm}$ PMSF, $5 \mu \mathrm{g} / \mathrm{ml}$ leupeptin, and 1 $\mu \mathrm{g} / \mathrm{ml}$ pepstatin $\mathrm{A}$, and centrifuged at $12,000 \mathrm{rpm}$ for $3 \mathrm{~min}$. The supernatant was placed in a centrifuge tube and mixed with an equal volume of
$80 \%$ sucrose. The samples were overlaid with $30 \%$ and $5 \%$ sucrose, respectively. The gradient was centrifuged at $130,000 \times g$ (average) for 20 $\mathrm{hr}$ and aliquoted into eight fractions, $0.60 \mathrm{ml}$ each, with fraction 1 being the uppermost (lightest) fraction. Lipid raft-containing fractions were tracked by the enrichment of the cholesterol binding protein, caveolin-1, and the dendritic lipid raft marker, flotillin-1.

Immunoblot analysis. Immunoprecipitates or equal amounts of protein in lysates were resolved on $8.5 \%$ SDS-PAGE, transferred to polyvinylidene fluoride membranes, and placed in blocking buffer $(0.1 \%$ Tween 20, 0.4\% I-block in PBS; Applied Biosystems) for $1 \mathrm{hr}$ (Keane et al., 1997). Membranes were then incubated with primary antibodies followed by the appropriate secondary antibody. Visualization of the signal was by enhanced chemiluminescence using a Phototope-HRP Detection Kit (Cell Signaling). To control for protein loading, the immunoblots were stripped with Restore, Western blotting stripping buffer (Pierce, Rockford, IL), and probed for $\beta$-tubulin. Quantification of bands corresponding to changes in protein levels was made using scanned densitometric analysis and NIH Image Program 1.62f. Band densities were analyzed by one-way ANOVA followed by appropriate post hoc comparisons.

Immunoprecipitation. Sections $\left(2 \mathrm{~mm}^{2}\right)$ of cerebral cortices $(n=5$ per group) were homogenized in PTN 50 buffer containing $10 \mathrm{~mm}$ DTT, 1 mм PMSF, $5 \mu \mathrm{g} / \mathrm{ml}$ leupeptin, and $1 \mu \mathrm{g} / \mathrm{ml}$ pepstatin A on ice for $30 \mathrm{~min}$. Lipid raft fractions were isolated, and equal amounts of protein in raft fractions were precleared with Protein G (Amersham Biosciences, Piscataway, NJ) for $1 \mathrm{hr}$, according to the manufacturer's instructions. Samples were incubated with the appropriate polyclonal antibodies, rotated overnight at $4^{\circ} \mathrm{C}$, and washed six times in lysis buffer. The beads were pelleted by centrifugation, resuspended in loading buffer, and heated to $95^{\circ} \mathrm{C}$ for 3 min before analysis by immunoblotting using monoclonal antibodies.

\section{Results}

\section{TBI induces an increase in TNFR1 and signaling}

\section{intermediates in the injured cortex}

TNF action in vivo depends on tissue type, precise cellular content, TNFR1 composition, and timing and duration of TNF action (Wajant et al., 2003). Our previous work shows a significant increase in TNF- $\alpha$ mRNA and protein in cellular lysates of injured cortex $1 \mathrm{hr}$ after moderate fluid-percussion TBI (Vitarbo et al., 2004). To dissect the contribution of the TNF ligand-receptor systems to TBI-induced pathology, the time course of expression of TNFR1 signaling intermediates was determined in cortical lysates ipsilateral (I) and contralateral (C) to injury (Fig. 1). Increased levels of TNFR1 were present in cortical lysates ipsilateral but not contralateral to injury within $5 \mathrm{~min}$ after TBI, and levels in lysates on the injury side continued to rise thereafter. In contrast, little or no change in levels of TNFR2 was observed in cortical lysates from both hemispheres. Thus, TNFR signaling after TBI appears to rely on increased TNFR1 expression.

Associated with early increases in TNFR1 expression in ipsilateral cortices was increased expression of the adaptor proteins TRADD, TRAF1, TRAF2, cIAP-2, the activated form of caspase-8, and the kinases IKK $\alpha$ and IKK $\beta$. Levels of RIP and FADD in lysates at various times after TBI did not show variation, however, and remained similar to naive controls. These results provide evidence that parasagittal fluid-percussion brain injury stimulates expression of TNFR1 and signaling molecules in cortices from the vulnerable ipsilateral hemisphere.

\section{TNFR1 but not TNFR2 or Fas is recruited into lipid rafts early after TBI}

To investigate whether lipid rafts are involved in TNF- $\alpha$ and Fas-mediated clustering of receptors and initiation of the respective signal transduction pathways, lipid rafts were isolated from traumatized cortices at $15 \mathrm{~min}$ after TBI by discontinuous su- 
crose density gradients (Fig. 2). Light fractions of the gradient were enriched in the lipid raft marker, caveolin-1, and the dendritic lipid raft marker, flotillin-1 (Fig. $2 A)$. Although a small amount of TNFR1 receptor was associated with lipid rafts from naive animals ( $8 \%$ by densitometry; $n=5$ ) (Fig. $2 B$ ), most of the receptor was excluded from microdomains. Moreover, Fas and TNFR2 were not detected in lipid rafts in naive animals. Association of TNFR1 with lipid rafts was greatly increased (35\%; $n=5)$ after TBI (Fig. 2 B), whereas Fas and TNFR2 did not associate with lipid microdomains. Thus, a small portion of TNFR1 is constitutively expressed in lipid rafts in the naive brain, and TBI signals rapid recruitment of TNFR1 to the rafts.

\section{TBI shifts TNFR1 and signaling} intermediates into lipid rafts, but IKK signaling molecules are not recruited Next, we investigated whether the partitioning of TNFR1 signaling components into lipid rafts changed after TBI. Discontinuous sucrose gradients were used to separate lipid rafts (R) from soluble membranes (S), and fractions were blotted using a panel of antibodies specific for proteins in the TNFR1 signaling transduction pathway (Fig. 3). A significant translocation of TNFR1 to lipid rafts was observed as early as 5 min after TBI and declined by 60 min after injury. Additionally, a substantial fraction of adaptor molecules TRADD, TRAF1, TRAF2, FADD, the kinase RIP, cIAP-1, and cIAP-2 partitioned into lipid rafts by $5 \mathrm{~min}$ after injury, whereas caspase- 8 was detected in rafts by $30 \mathrm{~min}$. In contrast, neither IKK $\alpha$ nor IKK $\beta$ was detected in raft-containing fractions, although these kinases were present in soluble fractions of naive and injured cortices. Interestingly, raft translocation of TRADD, TRAF1, TRAF2, FADD, cIAP-1, and CIAP-2 was accompanied by modification of proteins as they migrated with different molecular weights on SDS-PAGE. Thus, TNFR1 signaling in the cerebral cortex after TBI involves early recruitment of TNFR1 and adaptor components to rafts, but IKK signaling molecules are not shifted. Moreover, recruitment of caspase- 8 to lipid rafts seems to be a later event.

TBI induces dynamic changes in the composition of the TNFR1-associated signaling complexes in lipid rafts

When proteins are present in lipid rafts, self-association of those proteins is favored compared with that of proteins excluded from lipid rafts (Friedrichson and Kurzchalia, 1998). To assess the protein composition and association of adaptor proteins in TNFR1 signaling complexes, lipid rafts were isolated and immunoprecipitated with anti-TNFR1 antibody (Fig. 4). In naive cortices, TRADD, TRAF1, TRAF2, RIP, and CIAP-1 were immunoprecipitated with TNFR1; however, FADD, cIAP-2, and caspase- 8 were not detected in this signaling complex. Within 5 min after TBI,
TBI

$\frac{\text { Naive }}{\text { I C }} \frac{5^{\prime}}{\text { I C }} \frac{1^{15^{\prime}}}{\text { I C C }} \frac{30^{\prime}}{\text { I C C I C }} \frac{60^{\prime}}{\text { I C }}$

Band Intensity

(Relative Density Units)

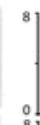

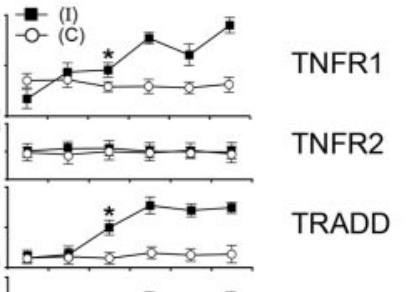

TRAF1

TRAF2

RIP

FADD

clAP-1

clAP-2

Caspase-8

$\mathrm{IKK} \alpha$

IKK $\beta$

$\beta$-Tubulin

$5^{\prime} 15^{\prime} 30^{\prime} 60^{\prime} 4 \mathrm{~h}$$$
\beta-1
$$

Figure 1. TBI induces TNFR1 signaling intermediates in the injured cortex. Immunoblot analysis of TNFR1, TNFR2, TRADD, TRAF1, TRAF2, RIP, FADD, CIAP-1, CIAP-2, caspase-8, IKK $\alpha$, and IKK $\beta$ proteins after TBI. Rats were subjected to moderate TBI, and

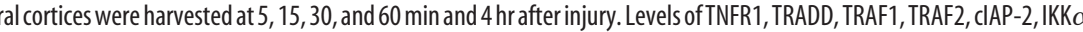
significant increases in protein levels were measured. ${ }^{*} p<0.05$ versus contralateral; error bars represent \pm SDs. I, Ipsilateral (injury) cortex; C, contralateral cortex.

the composition of the signaling complex changed. Notably, a substantial loss of TNFR1-associated adaptors RIP and cIAP-1 was observed, whereas increased association of FADD and cIAP-2 with TNFR1 was detected in lipid rafts of traumatized cortices. TNFR1 and TRAF1 also underwent extensive posttranslational modification in lipid microdomains. These changes were not detected in total cell lysates (Fig. 1). Additionally, caspase-8 was readily detected in TNFR1 immunoprecipitates in a timedependent manner, suggesting participation of this apical caspase in TNFR1 signaling in the traumatized brain. AntiTNFR1 did not immunoprecipitate the raft-associated protein, flotillin-1, demonstrating antibody specificity and thus serving as a control. These findings suggest that TBI-driven translocation of TNFR1 into lipid rafts promotes formation of receptorassociated signaling complexes that regulate different biological outcomes dictated by these complexes.

TNFR1 and TRAF1 are ubiquitinated in lipid rafts after TBI Ubiquitination of proteins is an important means of regulating their function, activity, localization, and degradation (Hicke, 2001). Because ubiquitination has been shown to play a role in receptor internalization and degradation, the protein modifica- 


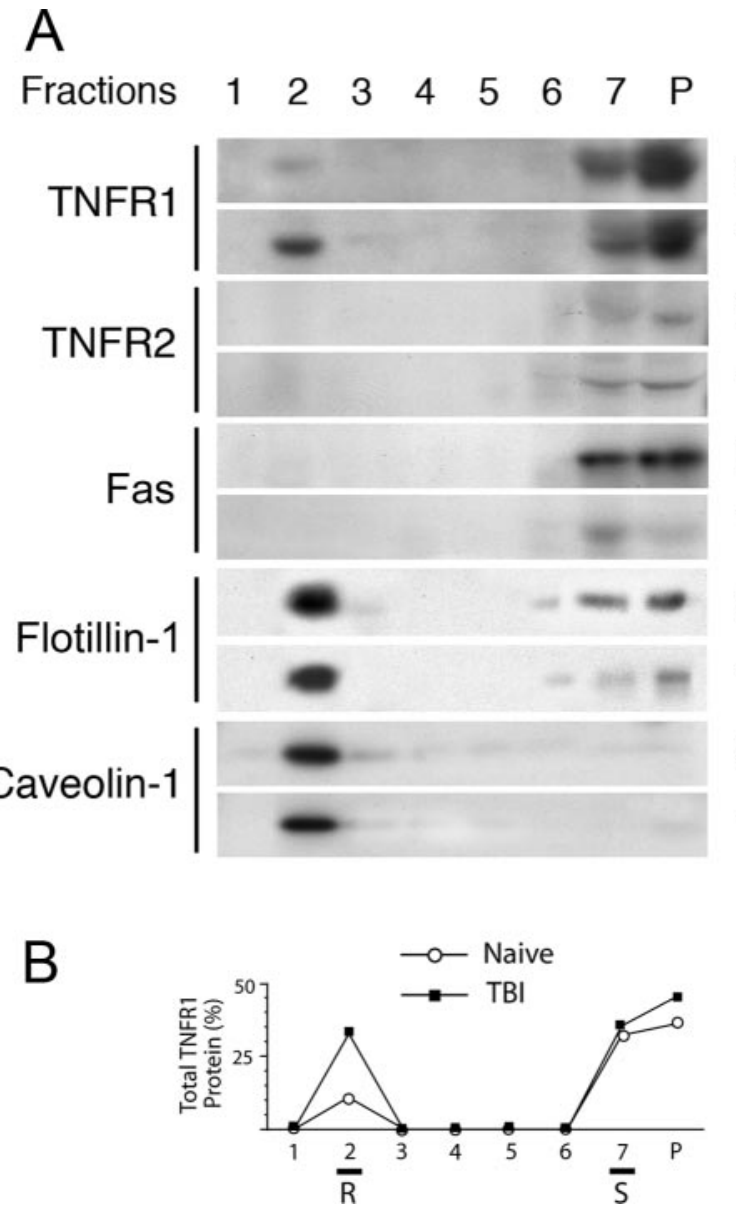

Figure 2. Partitioning of TNFR1 in lipid rafts. $A$, Cortical samples from naive and traumatized brains at 15 min after injury were lysed in $1 \%$ Triton X-100 and subjected to sucrose density centrifugation to isolate lipid rafts. Proteins of equal volume of representative collected fractions were separated by SDS-PAGE and analyzed by immunoblotting using specific antibodies against TNFR1, TNFR2, Fas, flotillin-1, and caveolin-1. B, Quantification of the total TNFR1 protein in naive and TBI groups. $R$, Raft; $S$, soluble fractions; $P$, pellet.

tion of TNFR1 and TRAF1 may be the addition of ubiquitin. To test this possibility, TNFR1 was immunoprecipitated from lipid rafts and immunoblotted using a ubiquitin-specific antibody (Fig. 5). Immunoblots of the immunoprecipitated complex from naive cortices revealed the presence of ubiquitinated proteins with apparent molecular weights corresponding to $55-75 \mathrm{kDa}$ in the signaling complex of microdomains. Within 5 min after TBI there was an increase in the presence of ubiquitinated proteins with apparent molecular weights ranging from 55 to $140 \mathrm{kDa}$. In contrast, ubiquitinated TNFR1 was not immunoprecipitated from soluble fractions (Fig. 5A). Moreover, ubiquitination of TRAF1 was observed in lipid rafts, but not soluble fractions, by immunoprecipitation of ubiquitinated molecules (molecular weights $52-110 \mathrm{kDa}$ ) using an anti-ubiquitin antibody (Fig. 5B). Subsequent immunoblotting using specific antibody clearly revealed that both TNFR1 and TRAF1 were ubiquitinated in lipid rafts but not nonraft regions of the plasma membrane after TBI.

\section{TBI induces NF- $\kappa$ B activation in the TNF- $\alpha$ signaling pathway}

Recruitment of TRADD, RIP, and TRAF2 to the TNF- $\alpha$ signaling complex mediates $\mathrm{I} \kappa \mathrm{B} \alpha$ kinase and subsequent NF- $\kappa \mathrm{B}$ activation (Karin and Ben-Neriah, 2000; Legler et al., 2003). NF- $\kappa$ B/Rel transcription factors are present in the cytosol in an inactive state,

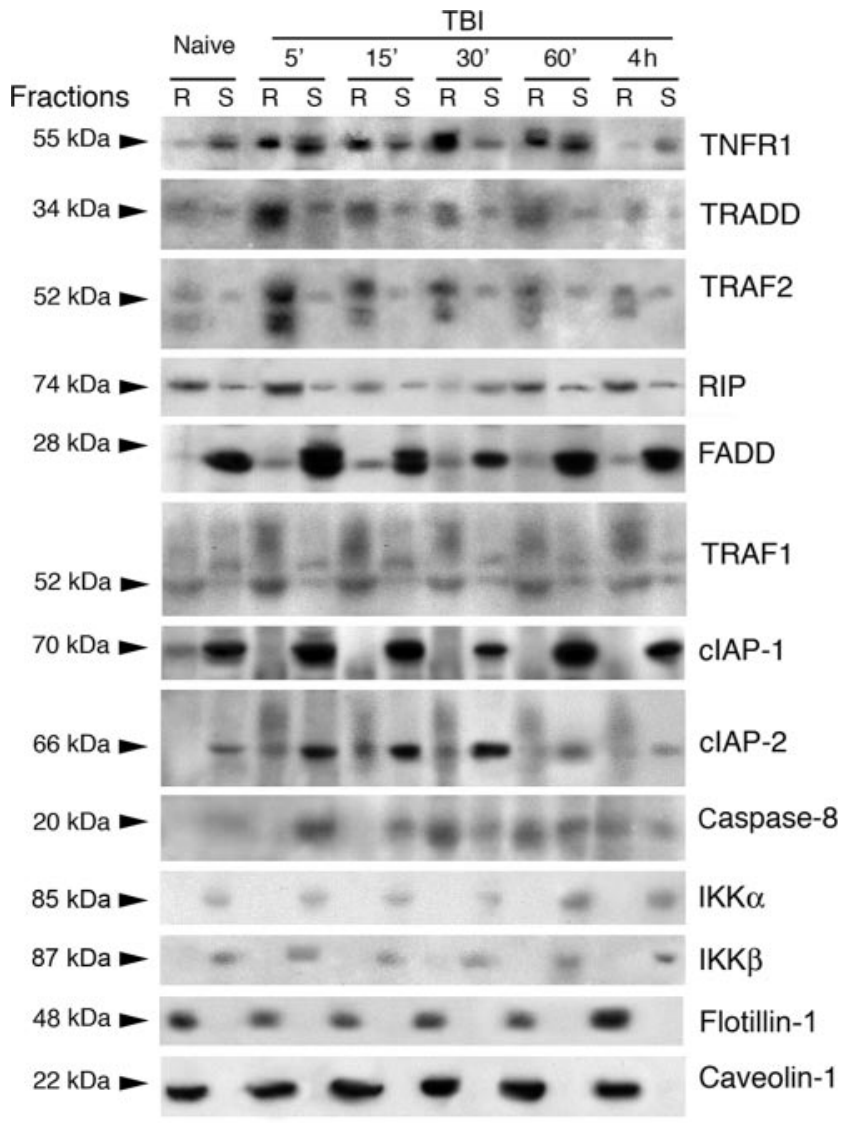

Figure 3. TBl induces recruitment of signaling molecules into lipid rafts. Rats were subjected to moderate $T B I$, and cortices were harvested at 5, 15, 30, and 60 min and $4 \mathrm{hr}$ after injury. Triton $\mathrm{X}$-100 soluble (S) and insoluble lipid raft (R) fractions were isolated. Equal aliquots of the fractions were subjected to SDS-PAGE, and the protein distribution was assessed by immunoblotting using specific antibodies against TNFR1, TRADD, TRAF1, TRAF2, RIP, FADD, CIAP-1, CIAP-2, caspase-8, IKK $\alpha$, IKK $\beta$, flotillin-1, and caveolin-1.

complexed with the inhibitory $\mathrm{I} \kappa \mathrm{B}$ proteins. After TNF- $\alpha$ stimulation, I $\kappa$ Bs are phosphorylated by the IKK complex, which results in subsequent ubiquitination and degradation by the proteasome, thus releasing NF- $\kappa \mathrm{B}$ for translocation into the nuclear compartment. To analyze NF- $\kappa \mathrm{B}$ activation, we measured the phosphorylation of I $\kappa$ B- $\alpha$ (Fig. 6). TBI-induced phosphorylation of $\mathrm{I} \kappa \mathrm{B}-\alpha$ was observed 5 and 15 min after injury in injured cortices, whereas little or no phosphorylation of I $\kappa \mathrm{B}-\alpha$ was seen in cortices from injured animals at later times after injury and in naive controls. Thus, it appears that TBI induces an early transient activation of the NF- $\kappa \mathrm{B}$ signal transduction pathway in the cerebral cortex that is abrogated within $30 \mathrm{~min}$ after injury. Moreover, NF- $\kappa \mathrm{B}$ activation occurs independently of lipid rafts (Fig. 3).

\section{Discussion}

In vitro studies have shown that lipid rafts play a crucial role in signal transduction of death receptors, such as TNFR1 and Fas/ CD95 (Ko et al., 1999; Simons and Toomre, 2000; Cottin et al., 2002; Legler et al., 2003; Muppidi and Siegel, 2004). Whether signals induced by TNFR family members in vivo, specifically in the CNS, also depend on these specialized membrane microdomains has not been analyzed in detail. Our study investigated the role of lipid rafts in signal transduction events of TNFR1, TNFR2, and Fas, three members of the TNFR superfamily implicated in 
IP: TNFR1

Blot:

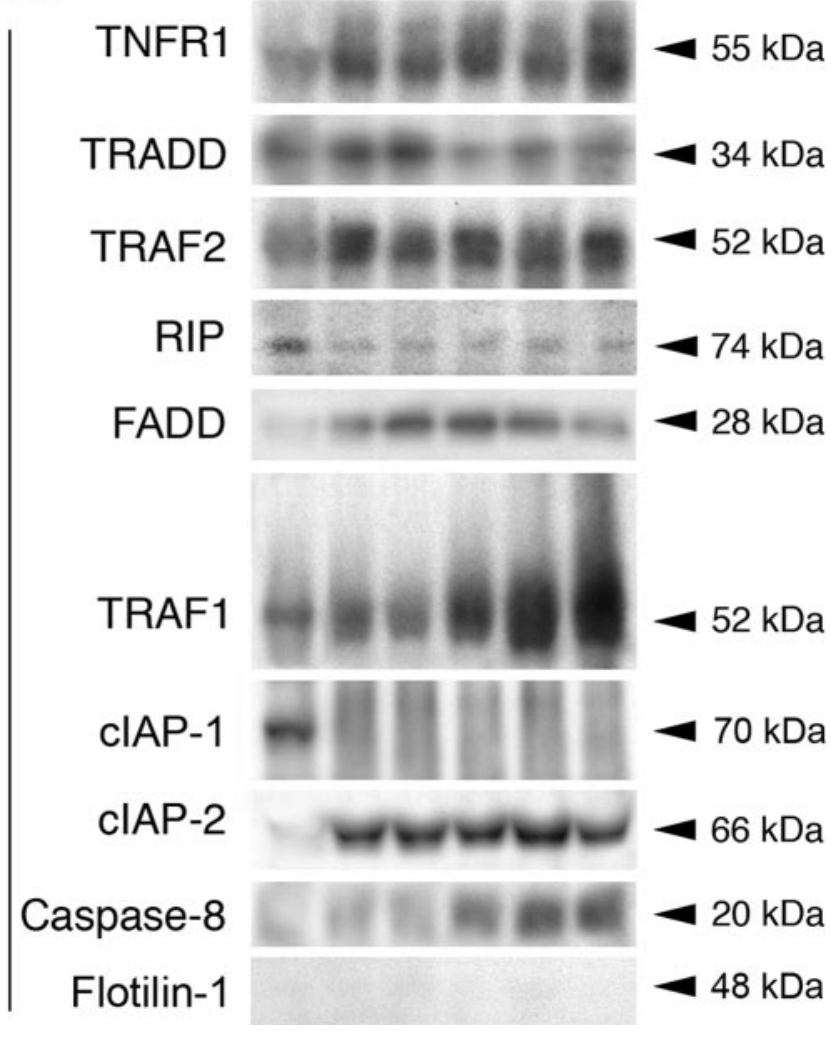

Figure 4. Association of TNFR1 with signaling intermediates in lipid rafts after TBI. Coimmunoprecipitation with TNFR1 of raft fractions of naive lysates and lysates obtained at 5, 15, 30, and $60 \mathrm{~min}$ and $4 \mathrm{hr}$ after TBI. TNFR1 immunoprecipitates were blotted for TNFR1, TRADD, TRAF2, RIP, FADD, TRAF1, CIAP-1, CIAP-2, and caspase-8. Raft-associated protein flotillin-1 served as control. N, Naive control groups.

neurodegenerative and inflammatory responses in the CNS (Choi and Benveniste, 2004).

Our data provide evidence that a rapidly formed signaling complex assembling around TNFR1, but not Fas or TNFR2, in lipid rafts determines TNF- $\alpha$ signaling after TBI. The results presented in this paper support the model outlined in supplemental Figure 1 (available at www.jneurosci.org as supplemental material). In the normal cortex, a small amount of TNFR1 constitutively localizes in microdomains, suggesting that the ordered state of lipid rafts provides a platform through which interactions with signaling intermediates are favored. TNFR1-signaling complexes in lipid rafts in normal cortices contained adaptor molecules TRADD, RIP, TRAF1, TRAF2, and cIAP-1. It is well known that the TNFR1-TRADD-RIP-TRAF2 complex initiates the pathway leading to survival (Hsu et al., 1996; Wajant et al., 2003), supporting the idea that the TNFR1 signaling complex in the normal cortex initiates a survival signal. Moreover, this signaling complex is devoid of FADD, cIAP-2, and caspase-8.

TBI induced rapid translocation of TNFR1 to lipid rafts, altered associations with signaling intermediates, and induced a transient activation of NF- $\kappa \mathrm{B}$. These observations are in agreement with partitioning of TNFR1 in lipid rafts of fibroblasts (Veldman et al., 2001), human fibrosarcoma cells (Legler et al., 2003), and primary cultures of mouse macrophages (Doan et al., 2004) after TNF- $\alpha$ activation. RIP and cIAP-1 dissociate from TNFR1, whereas FADD and CIAP-2 increase association with this
A

\section{IP: TNFR1 \\ Blot: Ubq}

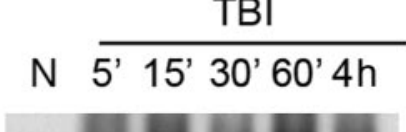

Rafts
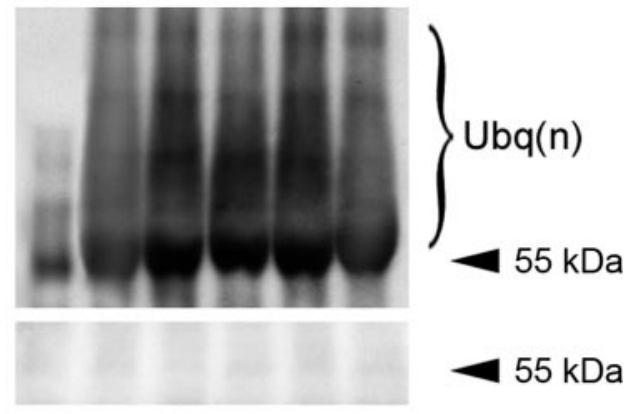

Soluble

$55 \mathrm{kDa}$

B

\section{IP: Ubq \\ Blot: TRAF1}

Rafts

\section{Soluble}

TBI
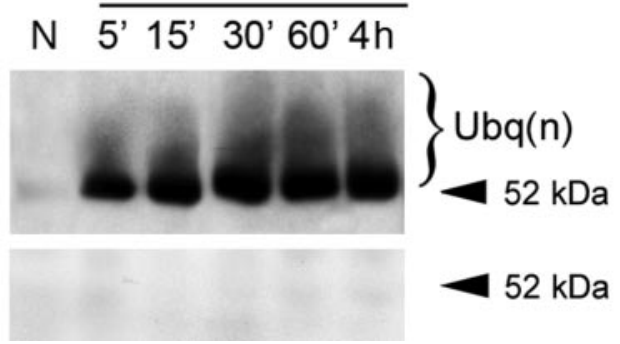

Figure 5. TBI-induced TNFR1 and TRAF1 ubiquitination in lipid rafts. Lipid rafts and soluble fractions were isolated from injured cortices and immunoprecipitated with TNFR1 $(A)$ and ubiquitin $(\mathrm{Ubq})(B)$. Ubiquitinated proteins were analyzed by immunoblotting using antibodies against Ubq $(A)$ and TRAF1 $(B)$. Polyubiquitinated proteins are denoted as Ubq(n). N, Naive control groups.

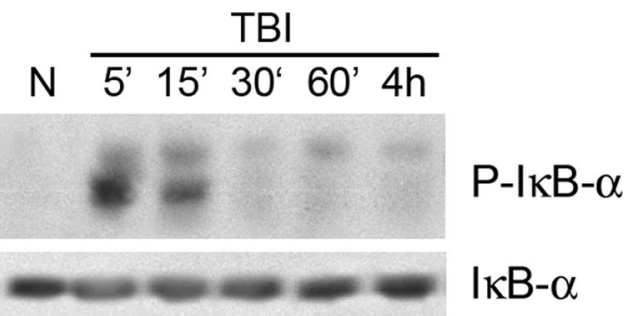

Figure 6. TBI induces NF- $\kappa B$ activation early after injury. Naive $(N)$ and injured cortical lysates were subjected to immunoblotting, and NF- $\kappa$ B activation was monitored by the phosphorylation of $\left.\right|_{\kappa \mathrm{B}}-\alpha\left(\mathrm{P}-\left.\right|_{\kappa} \mathrm{B}-\alpha\right)$. The same blot was reprobed with an antibody to total $I_{\kappa} \mathrm{B}-\alpha$ as internal control for protein loading.

receptor-signaling complex in lipid rafts. Because the TNFR1TRADD-FADD complex initiates the pathway leading to apoptosis (Hsu et al., 1996), it is possible that alterations in associations of adaptor molecules in the signaling complex are responsible for the switch in the signal transduction pathway from survival in the normal brain toward apoptosis after TBI. The recruitment of RIP by TRAF2 elicits activation of NF- $\kappa \mathrm{B}$ and JNK, respectively (Hsu et al., 1996; Ting et al., 1996; Devin et al., $2000)$. The crucial role of RIP in the activation of NF- $\kappa$ B has been demonstrated in RIP-deficient mice that are unable to activate NF- $\kappa$ B after TNF- $\alpha$ treatment (Kelliher et al., 1998). Thus, dissociation of RIP from the TNFR1 signaling complex induced by TBI may ablate or downregulate the NF- $\kappa$ B pathway and facilitates cell death. Additionally, cIAP-1, cIAP-2, and TRAF1 have been identified as NF- $\kappa$ B target genes (Wang et al., 1998; Schwenzer et al., 1999). TBI-induced interference of the NF- $\kappa$ B pathway 
may result in altered actions of the caspase- 8 inhibitory TNFR1TRAF-IAP complex to further promote apoptosis (Wajant et al., 2003). By $30 \mathrm{~min}$ after TBI, caspase- 8 was present in TNFR1 signaling complexes in injured cortices, supporting the idea that the association of FADD with TRADD initiates the apoptotic program by recruiting caspase- 8 .

Another TNFR1-selective apoptosis-regulating process is the TRAF2 recruitment of the anti-apoptotic cIAP-1 and cIAP-2 proteins to TNFR1 (Shu et al., 1996; Fotin-Mleczek et al., 2002). cIAP-1 and the closely related cIAP-2 were originally identified as molecules present in the TNFR2 signaling complex (Rothe et al., 1995). In the TNFR1 signaling complex, TRAF2-bound cIAP-1 and -2 molecules are able to block activation of caspase- 8 , which is independently recruited into the TNFR1 signaling complex via the TRADD-FADD axis (Roy et al., 1997; Wajant et al., 2003). The data presented here confirm and extend these observations and demonstrate that after TBI, cIAP-1 dissociates and cIAP-2 increases association with TNFR1 in the cholesterolsphingolipid-enriched membrane microdomains. In support of this observation, the TNFR1 signaling complex during seizureinduced neuronal death contains cIAP-2 (Shinoda et al., 2003). Thus, the amount of cIAP-1 or cIAP-2 recruited to the engaged TNFR1 is critical for the net function of the signaling complex; however, our data do not reveal whether the extensive modifications of adaptor proteins seen after TBI mediate associations of cIAPs with the receptor complex.

TNFR1 but not Fas shifts into lipid rafts after ligand engagement in the human fibrosarcoma cell line HT 1080 (Legler et al., 2003). In this in vitro model, the TNFR1 receptor-associated complex (complex I) that contains TRADD, RIP1, TRAF1, TRAF2, and cIAP-1 facilitates recruitment of IKK $\alpha$ and IKK $\beta$, resulting in activation of NF- $\kappa \mathrm{B}$. TNFR1-mediated apoptosis signaling is induced in a second step in which TRADD and RIP1 associate with FADD and caspase- 8 to form a cytoplasmic complex (complex II) that dissociates from TNFR1 (Micheau and Tschopp, 2003). Our in vivo studies do not reveal whether the pro-apoptotic complex II plays an essential role in the regulation of TNF- $\alpha$ responses after TBI, but rather indicate that in both normal and traumatized brains, lipid rafts appear to promote the formation of receptor-associated signaling complexes (complex I) to produce different biological outcomes dictated by these complexes. In contrast to TNFR1 complex I in human fibrosarcoma cells (Micheau and Tschopp, 2003) and those present in normal rat cortices, complex I from traumatized brains harbors activated caspase- 8 by $30 \mathrm{~min}$ after TBI, indicating involvement of downstream signaling cascades. Thus, after TBI, the death domain of TRADD may act as a central platform for the recruitment and activation of FADD, leading to subsequent binding of caspase- 8 and triggering their activation (close proximity model) (Boatright et al., 2003). Clearly, early activation of initiator caspases- 8 and -9 and effector caspase- 3 has been associated with apoptosis in this TBI animal model (Keane et al., 2001), supporting this idea.

TNF family members induce apoptosis that is tightly regulated by genes activated by NF- $\kappa \mathrm{B}$, and modulation of the responses in favor of NF- $\kappa \mathrm{B}$ protects cells from apoptosis. Therefore, cells unable to activate the NF- $\kappa$ B pathway and synthesize anti-apoptotic proteins such as IAPs and TRAFs (Wang et al., 1998) would undergo apoptosis when stimulated by TNF- $\alpha$. Our studies show that TBI induced a rapid transient activation of $\mathrm{NF}-\kappa \mathrm{B}$, but the signaling molecules involved in NF- $\kappa \mathrm{B}$ activation were mostly excluded from lipid rafts in cerebral cortices of naive and injured animals. These findings are in agreement with results of a recent study in primary macrophage cultures that demonstrated that I- $\kappa \mathrm{B}$ kinase $-\gamma$ and $\mathrm{I}-\kappa \mathrm{B}-\alpha$ are excluded from raftcontaining fractions after TNF- $\alpha$ stimulation (Doan et al., 2004) but differ from results in the fibrosarcoma cell line, HT-1080, in which NF- $\kappa$ B signaling intermediates were present in lipid rafts and TNF- $\alpha$-induced activation of NF- $\kappa \mathrm{B}$ was blocked by cholesterol depletion (Legler et al., 2003). Because TNFR1 is localized to lipid rafts and nonraft regions of the plasma membrane, each compartment may be capable of initiating different signaling responses. Further studies that disrupt lipid rafts are clearly needed to determine whether spatially segregated signaling modules are assembled into active signaling complexes in vivo. Moreover, Doan and colleagues (2004) raise the intriguing possibility that different cell types use lipid rafts in different ways to regulate TNFR1 signaling. Because TNFR1 is expressed on neurons, astrocytes, and oligodendrocytes (Dopp et al., 1997; Yang et al., 2002; Yan et al., 2003), it is possible that the dynamic composition of the raft and nonraft regions of the plasma membrane of different types of CNS cells may play an important role in specifying responses induced by TNFR1; however, future studies are needed to determine the consequence of TNFR1-induced signaling in lipid rafts in purified CNS cell populations to test this hypothesis.

Posttranslational modifications of several complex-associated proteins occur in lipid rafts in traumatized cortices. For example, TNFR1 in the normal cortex exhibits an apparent molecular weight of $55 \mathrm{kDa}$, but after TBI it forms molecular species with apparent molecular weight ranging from 55 to $140 \mathrm{kDa}$. Moreover, a large proportion of TRAF 1 present in lipid rafts undergoes modifications that increase its molecular weight from 52 to 110 $\mathrm{kDa}$ after trauma. Immunoprecipitation of the TNFR1 signaling complex I using specific antibodies for adaptor proteins and ubiquitin revealed that TNFR1 and TRAF1 modifications were the result of polyubiquitination presumably targeting these proteins for degradation via the proteasome pathway. Thus, microdomains play a critical role in the specific modification of TNFR1 and TRAF1 by ubiquitin.

Our findings indicate that moderate TBI induces a rapid recruitment of TNFR1 into lipid rafts and that lipid rafts serve as platforms for TNFR1 signaling in the normal and traumatized cortex by recruiting adaptor molecules to microdomains. In addition, these microdomains play a role in the specific modifications and recruitment of adaptor proteins in the cortex induced by TBI. Dynamic regulation of raft localization of TNFR1 may prove a mechanism by which cells can become intrinsically more sensitive to TNF-mediated stimuli. Modifying the raft location of TNFR1 offers a potential therapeutic strategy to target cell death mechanisms after brain injury.

\section{References}

Boatright KM, Renatus M, Scott FL, Sperandio S, Shin H, Pedersen IM, Ricci JE, Edris WA, Sutherlin DP, Green DR, Salvesen GS (2003) A unified model for apical caspase activation. Mol Cell 11:529-541.

Bruce AJ, Boling W, Kindy MS, Peschon J, Kraemer PJ, Carpenter MK, Holtsberg FW, Mattson MP (1996) Altered neuronal and microglial responses to excitotoxic and ischemic brain injury in mice lacking TNF receptors. Nat Med 2:788-794.

Choi C, Benveniste EN (2004) Fas ligand/Fas system in the brain: regulator of immune and apoptotic responses. Brain Res Brain Res Rev 44:65-81.

Clark WM, Lutsep HL (2001) Potential of anticytokine therapies in central nervous system ischaemia. Expert Opin Biol Ther 1:227-237.

Cottin V, Doan JE, Riches DW (2002) Restricted localization of the TNF receptor CD120a to lipid rafts: a novel role for the death domain. J Immunol 168:4095-4102.

Devin A, Cook A, Lin Y, Rodriguez Y, Kelliher M, Liu Z (2000) The distinct 
roles of TRAF2 and RIP in IKK activation by TNF-R1: TRAF2 recruits IKK to TNF-R1 while RIP mediates IKK activation. Immunity 12:419-429.

Doan JE, Windmiller DA, Riches DW (2004) Differential regulation of TNF-R1 signaling: lipid raft dependency of p42mapk/erk2 activation, but not NF-kappaB activation. J Immunol 172:7654-7660.

Dopp JM, Mackenzie-Graham A, Otero GC, Merrill JE (1997) Differential expression, cytokine modulation, and specific functions of type- 1 and type-2 tumor necrosis factor receptors in rat glia. J Neuroimmunol 75:104-112.

Fan L, Young PR, Barone FC, Feuerstein GZ, Smith DH, McIntosh TK (1996) Experimental brain injury induces differential expression of tumor necrosis factor-alpha mRNA in the CNS. Brain Res Mol Brain Res 36:287-291.

Fotin-Mleczek M, Henkler F, Samel D, Reichwein M, Hausser A, Parmryd I, Scheurich P, Schmid JA, Wajant H (2002) Apoptotic cross talk of TNF receptors: TNF-R2 induces depletion of TRAF2 and IAP proteins and accelerates TNF-R1-dependent activation of caspase-8. J Cell Sci 115:2757-2770

Friedrichson T, Kurzchalia TV (1998) Microdomains of GPI-anchored proteins in living cells revealed by crosslinking. Nature 394:802-805.

Hicke L (2001) A new ticket for entry into budding vesicles-ubiquitin. Cell 106:527-530.

Hsu H, Xiong J, Goeddel DV (1995) The TNF receptor 1-associated protein TRADD signals cell death and NF-kappa B activation. Cell 81:495-504.

Hsu H, Shu HB, Pan MG, Goeddel DV (1996) TRADD-TRAF2 and TRADD-FADD interactions define two distinct TNF receptor 1 signal transduction pathways. Cell 84:299-308.

Karin M, Ben-Neriah Y (2000) Phosphorylation meets ubiquitination: the control of NF-kappa B activity. Annu Rev Immunol 18:621-663.

Keane RW, Srinivasan A, Foster LM, Testa MP, Ord T, Nonner D, Wang HG, Reed JC, Bredesen DE, Kayalar C (1997) Activation of CPP32 during apoptosis of neurons and astrocytes. J Neurosci Res 48:168-180.

Keane RW, Kraydieh S, Lotocki G, Alonso OF, Aldana P, Dietrich WD (2001) Apoptotic and antiapoptotic mechanisms after traumatic brain injury. J Cereb Blood Flow Metab 21:1189-1198.

Kelliher MA, Grimm S, Ishida Y, Kuo F, Stanger BZ, Leder P (1998) The death domain kinase RIP mediates the TNF-induced NF-kappaB signal. Immunity 8:297-303.

Kim GM, Xu J, Song SK, Yan P, Ku G, Xu XM, Hsu CY (2001) Tumor necrosis factor receptor deletion reduces nuclear factor- $\kappa \mathrm{B}$ activation, cellular inhibitor of apoptosis protein 2 expression, and functional recovery after traumatic spinal cord injury. J Neurosci 21:6617-6625.

Ko YG, Lee JS, Kang YS, Ahn JH, Seo JS (1999) TNF-alpha-mediated apoptosis is initiated in caveolae-like domains. J Immunol 162:7217-7223.

Legler DF, Micheau O, Doucey MA, Tschopp J, Bron C (2003) Recruitment of TNF receptor 1 to lipid rafts is essential for TNFalpha-mediated NFkappaB activation. Immunity 18:655-664.

Li X, Yang Y, Ashwell JD (2002) TNF-RII and C-IAP1 mediate ubiquitination and degradation of TRAF2. Nature 416:345-347.

Liu ZG, Hsu H, Goeddel DV, Karin M (1996) Dissection of TNF receptor 1 effector functions: JNK activation is not linked to apoptosis while NFkappaB activation prevents cell death. Cell 87:565-576.

Lou J, Lucas R, Grau GE (2001) Pathogenesis of cerebral malaria: recent experimental data and possible applications for humans. Clin Microbiol Rev 14:810-820.

Martin-Villalba A, Hahne M, Kleber S, Vogel J, Falk W, Schenkel J, Krammer PH (2001) Therapeutic neutralization of CD95-ligand and TNF attenuates brain damage in stroke. Cell Death Differ 8:679-686.

Micheau O, Tschopp J (2003) Induction of TNF receptor I-mediated apoptosis via two sequential signaling complexes. Cell 114:181-190.

Muppidi JR, Siegel RM (2004) Ligand-independent redistribution of Fas (CD95) into lipid rafts mediates clonotypic T cell death. Nat Immunol 5:182-189.

Nawashiro H, Martin D, Hallenbeck JM (1997) Neuroprotective effects of TNF binding protein in focal cerebral ischemia. Brain Res 778:265-271.

Perry RT, Collins JS, Wiener H, Acton R, Go RC (2001) The role of TNF and its receptors in Alzheimer's disease. Neurobiol Aging 22:873-883.
Probert L, Akassoglou K (2001) Glial expression of tumor necrosis factor in transgenic animals: how do these models reflect the "normal situation"? Glia 36:212-219.

Ross SA, Halliday MI, Campbell GC, Byrnes DP, Rowlands BJ (1994) The presence of tumour necrosis factor in CSF and plasma after severe head injury. Br J Neurosurg 8:419-425.

Rothe M, Pan MG, Henzel WJ, Ayres TM, Goeddel DV (1995) The TNFR2TRAF signaling complex contains two novel proteins related to baculoviral inhibitor of apoptosis proteins. Cell 83:1243-1252.

Roy N, Deveraux QL, Takahashi R, Salvesen GS, Reed JC (1997) The c-IAP-1 and c-IAP-2 proteins are direct inhibitors of specific caspases. EMBO J 16:6914-6925.

Schwenzer R, Siemienski K, Liptay S, Schubert G, Peters N, Scheurich P, Schmid RM, Wajant H (1999) The human tumor necrosis factor (TNF) receptor-associated factor 1 gene (TRAF1) is up-regulated by cytokines of the TNF ligand family and modulates TNF-induced activation of NFkappaB and c-Jun N-terminal kinase. J Biol Chem 274:19368-19374.

Shinoda S, Skradski SL, Araki T, Schindler CK, Meller R, Lan JQ, Taki W, Simon RP, Henshall DC (2003) Formation of a tumour necrosis factor receptor 1 molecular scaffolding complex and activation of apoptosis signal-regulating kinase 1 during seizure-induced neuronal death. Eur J Neurosci 17:2065-2076.

Shohami E, Bass R, Wallach D, Yamin A, Gallily R (1996) Inhibition of tumor necrosis factor alpha (TNFalpha) activity in rat brain is associated with cerebroprotection after closed head injury. J Cereb Blood Flow Metab 16:378-384.

Shohami E, Gallily R, Mechoulam R, Bass R, Ben-Hur T (1997) Cytokine production in the brain following closed head injury: dexanabinol (HU211) is a novel TNF-alpha inhibitor and an effective neuroprotectant. J Neuroimmunol 72:169-177.

Shu HB, Takeuchi M, Goeddel DV (1996) The tumor necrosis factor receptor 2 signal transducers TRAF2 and c-IAP1 are components of the tumor necrosis factor receptor 1 signaling complex. Proc Natl Acad Sci USA 93:13973-13978.

Simons K, Toomre D (2000) Lipid rafts and signal transduction. Nat Rev Mol Cell Biol 1:31-39.

Taupin V, Toulmond S, Serrano A, Benavides J, Zavala F (1993) Increase in IL-6, IL-1 and TNF levels in rat brain following traumatic lesion. Influence of pre- and post-traumatic treatment with Ro5 4864, a peripheraltype (p site) benzodiazepine ligand. J Neuroimmunol 42:177-185.

Ting AT, Pimentel-Muinos FX, Seed B (1996) RIP mediates tumor necrosis factor receptor 1 activation of NF-kappaB but not Fas/APO-1-initiated apoptosis. EMBO J 15:6189-6196.

Tyor WR, Wesselingh SL, Griffin JW, McArthur JC, Griffin DE (1995) Unifying hypothesis for the pathogenesis of HIV-associated dementia complex, vacuolar myelopathy, and sensory neuropathy. J Acquir Immune Defic Syndr Hum Retrovirol 9:379-388.

Veldman RJ, Maestre N, Aduib OM, Medin JA, Salvayre R, Levade T (2001) A neutral sphingomyelinase resides in sphingolipid-enriched microdomains and is inhibited by the caveolin-scaffolding domain: potential implications in tumour necrosis factor signaling. Biochem J 355:859-868.

Vitarbo EA, Chatzipanteli K, Kinoshita K, Truettner JS, Alonso OF, Dietrich WD (2004) TNF- $\alpha$ expression and protein levels following fluid percussion injury in rats: the effect of injury severity and brain temperature. Neurosurgery 55:416-425.

Wajant H, Pfizenmaier K, Scheurich P (2003) Tumor necrosis factor signaling. Cell Death Differ 10:45-65.

Wang CY, Mayo MW, Korneluk RG, Goeddel DV, Baldwin Jr AS (1998) NF-kappaB antiapoptosis: induction of TRAF1 and TRAF2 and c-IAP1 and c-IAP2 to suppress caspase-8 activation. Science 281:1680-1683.

Yan P, Liu N, Kim GM, Xu J, Li Q, Hsu CY, Xu XM (2003) Expression of the type 1 and type 2 receptors for tumor necrosis factor after traumatic spinal cord injury in adult rats. Exp Neurol 183:286-297.

Yang L, Lindholm K, Konishi Y, Li R, Shen Y (2002) Target depletion of distinct tumor necrosis factor receptor subtypes reveals hippocampal neuron death and survival through different signal transduction pathways. J Neurosci 22:3025-3032. 